\title{
Exploring the felt sense of chronic ill-health: dialoguing between IPA, lifeworld theory and narrative inquiry to make sense of feelings and affect
}

\begin{abstract}
We present a pluralist approach to analysing emotion and affect within subjective lived experience. We illustrate this by re-engaging with data about living with Parkinson's disease (PD) to more fully understand the felt sense of chronic illhealth. Following Pierce, we engage in abductive reasoning to achieve this. The original data were generated using semi-structured interviews and analysed using Interpretative Phenomenological Analysis. This inductive, idiographic analysis was our starting point. We then engaged in a dialogue between theory and data to further explicate the felt sense. Using the phenomenological theory of lifeworld revealed the presence and significance of emotion throughout and revealed the co-existence of well-being and suffering within the felt sense of PD. A Narrative Oriented Inquiry examined in detail the narrative structure within the re-telling of the diagnosis and coming to terms with PD. Emotion was embedded in the account and revealed the prevailing mood within the experience.
\end{abstract}

Keywords: emotion; affect; chronic illness; phenomenology; narrative.

\section{Introduction}

In this paper, we explore a pluralist approach for making sense of the feelings,

affect and emotion imbued within subjective lived experiences of chronic ill-health. The 'affective turn' in psychology has thrown up a number of possibilities for methodological approaches to emotion, but as yet there is little explication of the compatibility of those approaches and their analytic implications. We propose a pluralist approach to data analysis which is grounded in phenomenology but which also prioritises interpretivism, through narrative, thus touching upon both the experiential thematising of emotion as well as the affective practices through which we engage to express or perform those emotions. This follows Frost's (2011) argument that there are benefits to conceptualising a phenomenon in different ways through more than one 
paradigmatic lens. Frost, Holt, Shinebourne, Esin, Nolas, Mehdizadeh, \& BrooksGordon (2011) argue that the variety of human expression cannot always be sufficiently represented by one method alone and it is at times better illustrated by different approaches used concurrently. Their investigation as part of Pluralism in Qualitative Research project (Frost, Nolas, Brooks-Gordon, Esin, Holt, Shinebourne \& Mehdizadeh, 2010) highlights the value of using different approaches to analyse data to provide a more holistic view of a described experience and provide more robust qualitative findings to seek to better understand an experience. With this in mind, we chose to illustrate this new approach to feeling and affect, by re-engaging with a dataset exploring families' experiences of living with Parkinson's disease (Smith \& Shaw, 2016). We take a fresh look by focusing on the 'felt sense' (Gendlin, 1981) of chronic ill-health, i.e. by examining the meanings attributed to, and the roles played by, the emotions embedded within participants' embodied experience to expand our understanding of this lived experience.

We are by no means the first to bring together phenomenology and narrative (e.g. Langdridge, 2007), which is not surprising given the close conceptual links between scholars like Ricœur (1985) and Heidegger (1962), for example, who both emphasise the situatedness of meaning, time, and agency within our human existence. We are also aware of on-going research which has taken a pluralist approach to understanding phenomena using discursive and phenomenological methods (Willig, 2017), which shows a maturity within qualitative psychology. Now that there is overwhelming support for qualitative research in psychology, researchers are becoming more creative in their methods. This opens up exciting new avenues for qualitative 
psychologists and presents opportunities for those of us with a fascination for epistemology and methodological innovation.

Historically, qualitative research has championed an inductive approach because of its commitment to prioritising the participants' voice in the theorisation of psychological phenomena and its concern with emancipation. We would like to propose an approach involving abductive reasoning, which instead of focusing on the 'bottomup' approach of inductive reasoning or the 'top-down' approach of the hypotheticdeductive method, engages in a two-way dialogue between the fresh data and established theory. Abductive reasoning, from Pierce (1903), uses whatever resources are at our disposal - data and theory - to find the best explanation available for our research findings (for further discussions of this third logic of critical explanation through abductive reasoning, see: Shaw \& Hiles, 2017; Glynos \& Howarth, 2007). In this paper, we draw on the phenomenological theory of the lifeworld (Galvin \& Todres, 2013) and narrative inquiry (Hiles, Čermák \& Chrz, 2017) to help make sense of the feelings, affect and emotion within the subjective experiences of chronic ill-health.

The lifeworld is a phenomenological concept developed by Husserl $(1936 / 1970)$ and has been taken on board in contemporary phenomenological research methods (e.g. Giorgi, 2009; Dahlberg, Dahlberg \& Nyström, 2008). The lifeworld is our 'beginning place' (Galvin \& Todres, 2013); it constitutes our relationship with the world, our cultural situation, our sensations, and our meaning-making. The lifeworld is made up of different dimensions which offer a holistic approach for understanding human experience as it is lived: temporality, spatiality, intersubjectivity, embodiment, identity, and mood. The notion of mood, or emotional attunement, is inherently linked to each dimension of the lifeworld and works to provide texture and colour to our lived feelings and affect. Qualitative Research in Psychology. DOI: 
experience. Ashworth (2006) described 'mood-as-atmosphere' as a feeling tone which underpins and penetrates all aspects of our lifeworld. As such, the phenomenological theory of the lifeworld conceives of emotion and affect as fundamental to our being-inthe-world and thus provides an excellent theoretical framework through which to explore their significance for qualitative research.

In order to examine this lifeworld more closely, a narrative approach has been undertaken in our study that is called Narrative Oriented Inquiry (NOI; Hiles, Čermák \& Chrz, 2017) which was inspired by a number of pioneers in the narrative field, including Labov \& Waletsky (1967), Mishler (1999, 1986), and Riessman (2008, 1993). At the heart of this methodology is the key notion of 'bounded' and 'unbounded' motifs that constitute narrative structure, originally pointed out by Herman \& Vervaeck (2001). The first step for this approach involves 'separating' the fabula (bounded) from the sjuzet (unbounded). The idea here is that some parts of narrative structure (i.e. the fabula) merely outline the temporal sequence of events being described, which if altered would fatally change the basic storyline, and are therefore recognised as "bounded". While other parts of narrative structure (i.e. the sjuzet) bring the story to life, animating and highlighting the significance that this re-telling of the story, in a particular way, on this particular occasion. In this way, the sjuzet can be seen as "colouring" the narrative for the particular occasion of its (re)telling, and is therefore is recognized as "unbounded". It emerges that a key feature of the sjuzet is that it is the primary vehicle for the expression of feeling, affect and emotion in relating experience, and this approach to narrative analysis fits particularly well with Galvin \& Todres' $(2013$, p.12) exploration of the lifeworld that involves "our sense of feeling, mood and emotion as the lens by which our worlds are coloured".

Shaw, R.L., Smith, L.J., \& Hiles, D. R. (2018). Exploring the felt sense of chronic-ill health: dialoguing between IPA, lifeworld theory and narrative inquiry to make sense of feelings and affect. Qualitative Research in Psychology. DOI: 10.1080/14780887.2018.1499839. 
Previous qualitative research about living with chronic conditions has focused on establishing experiential descriptions of diagnosis and self-management. Some of this work has used phenomenological methods to explore, for example, the experience of living with chronic obstructive pulmonary disease (Barnett, 2005) and chronic low back pain (Snelgrove \& Liossi, 2009; Smith \& Osborne, 2008). Other researchers have brought into focus the phenomenological theory of the lifeworld in order to capture the impact of chronic ill-health across the dimensions of the lifeworld (e.g. Haahr, Kirkevold, Hall \& Ostergaard, 2001; Gullick \& Stainton, 2008; Fine \& Glendinning, 2005). There is also a great deal of qualitative research using narrative theory or narrative analysis to make sense of experiences of chronic ill-health, following Bury's (2001) seminal work on illness as biographic disruption (e.g. Delbene, 2011; Pierret, 2003) and the conceptualisation of illness narratives (Shapiro, 2011; Reynolds \& Vivat, 2006). However, we have not identified any examples which have explicitly brought these two approaches together in the way we propose.

The subject of our worked example is the experience of living with Parkinson's disease (PD) within the context of the family unit (see Smith \& Shaw, 2016). People living with PD have described the diagnosis as 'dropping the bomb' because with the diagnosis come anxieties of an unknown future (Phillips, 2006). A new diagnosis brings the body into consciousness and this awareness can make the body appear alien (Ekra \& Gjengedal, 2012). A chronic health condition can also reduce the predictability and automatic nature of the body, bringing about feelings of loss, anxiety, panic or fear in all areas of life, impacting on patients' quality of life (Gullick \& Stainton, 2008; Barnett, 2005). In this re-visiting of the analysis, we focus on those expressions of 
emotion and affect, that felt sense, to demonstrate their fundamental basis to human experience.

\section{Method}

The data for the original study (Smith \& Shaw, 2016) came from semistructured interviews with four people diagnosed with PD and their partners, and one additional person whose partner had PD and was deceased. For the original study data were analysed using Interpretative Phenomenological Analysis (IPA; Smith, Flowers \& Larkin, 2009). This is an idiographic method drawing on hermeneutic phenomenology. Four themes were generated: It's more than just an illness, Like a bird with a broken wing, Being together with PD, and Carpe diem!. The analysis was inductive, prioritising participants' own meaning-making processes in order to understand their experience.

When we re-visited the data, we added two additional phases to the analytic process. Following the inductive IPA analysis, we identified a theory we felt was appropriate to help better explain the findings, thus engaging in abductive reasoning. As described above, the theory we chose was the phenomenological theory of the lifeworld. Our starting point was the themes identified in the IPA analysis. We then entered into a dialogue with Galvin \& Todres' (2013) lifeworld theory of well-being and suffering to further examine the meanings of living with PD.

\section{[insert Table 1 around here]}

Galvin \& Todres (2013) created two interconnecting descriptions of well-being (see Table 1) and suffering (see Table 2) across the elements of the lifeworld. These draw on Heidegger's (1993a, 1993b) notion of 'Gegnet' which brings together the concepts of 'dwelling' and 'mobility' in order to describe different possibilities for 
well-being and suffering. In relation to well-being, existential mobility opens up opportunities for moving forward with a sense of adventure; in relation to suffering, it represents a sense of being trapped, with no perceivable way out. Existential dwelling offers a sense of being 'at home', peacefulness, as experiences of well-being; in terms of suffering, it represents homelessness, disturbance, and dis-ease. For Heidegger, dwelling-mobility (or Gegnet) defines the co-existence of well-being and suffering those feelings of being at-home in one sense, but out of place, or homeless, in another. We examined the themes developed against these descriptions of well-being and suffering. This was a reflective, back-and-forth process of thinking through the content of each theme alongside the elements of the lifeworld (temporality, spatiality, intersubjectivity, embodiment, identity, and emotional attunement or mood). This phase is reported in the original paper (Smith \& Shaw, 2016) but for the purposes of this paper, we concentrate on the exposition of emotional attunement (or mood).

\section{[insert Table 2 around here]}

The second phase of the analysis involved adopting the techniques from NOI to conduct a fine-grained, micro analysis of the narrative structure of participants' accounts. For the original study, an individual relaxed in-depth interviewing style had been adopted, asking open-ended questions focussed on diagnosis and living with PD. Although this was not the classical "narrative interview" as proposed by Mishler (1986), it was clearly evident from the transcripts that participants would occasionally drop into an obvious storytelling mode of discourse. It was clear that in addition to answering interview questions directly, that all participants also used narrative modes of expression in answering at least some of the questions in the interview, especially to outline compelling and significant events they had experienced in being diagnosed, and 
in then learning to live with PD. These could be brief or expanded to considerable length. For the purposes of this paper, we illustrate this innovative abductive approach with one detailed example of this type of data analysis, which requires 'segmenting' the narrative into a sequence of temporal episodes, followed by 'separation' into fabula and sjuzet.

These two phases of abductive analysis using (i) the phenomenology of the lifeworld, and (ii) narrative theory, considerably extend the original findings from the IPA approach. The first two authors of this paper, a Health Psychologist with many years' experience of phenomenological research and a researcher with training in health psychology, focused on the interpretation of the data from a lifeworld-led perspective, and the third author, a psychologist with methodological expertise and one of the proposers of the NOI method, focussed on the NOI analysis. This was followed by several joint discussions of all of the findings with a view to integration as an example of abductive data analysis, making explicit the need for abductive strategies in qualitative data analysis to find the "best explanation" of the data, as well as its particular relevance and significance in the study of feelings, emotion and affect. We collaborated closely on this analysis and although the first two authors worked more closely on the lifeworld analysis, and the third on the NOI, we had discussions throughout, gave each other feedback, and each contributed to all stages of analysis, if only to offer agreement. We did not have any disagreements during this process, but if we had we would have reached a consensus through further discussion.

Shaw, R.L., Smith, L.J., \& Hiles, D. R. (2018). Exploring the felt sense of chronic-ill health: dialoguing between IPA, lifeworld theory and narrative inquiry to make sense of feelings and affect. Qualitative Research in Psychology. DOI: 10.1080/14780887.2018.1499839. 


\section{Results}

First, the findings are presented of the lifeworld analysis of emotional attunement; second, we present the results of the NOI.

\section{Lifeworld analysis of mood/emotional attunement}

On re-examining the participants' accounts, and reflecting back on data generation, it was clear that emotions were present throughout the process. Telling their stories evoked emotional responses from participants which were shown on their faces and heard in their voices; some displayed frustration and discomfort, but for others there was resolve. Participants seemed to be re-living the moments when their lives changed through the telling of them, which in turn, evoked emotional responses in the interviewer. This presence of 'live' emotion added depth and resonance to the process of creating and making sense of participants' stories, which is one reason we wanted to return to the data to further examine them. We now turn to the lifeworld analysis, which should be read in consultation with Tables 1 and 2 .

The "bombshell" of diagnosis identified by Phillips (2006) was repeated here.

Susan described the diagnosis as:

\footnotetext{
“A bit of a bombshell really but I think he had symptoms, which we wouldn't even have dreamt were Parkinson's symptoms, erm, knowing very little about it." (Susan, partner)
}

Here Susan's shock reflects a sense of agitation and unsettled restlessness (see Table 2), at the time of her partner's diagnosis with PD. This external interference into her lifeworld by PD is experienced as an invasion, something which disrupts her sense of peace and challenges her own life project.

Shaw, R.L., Smith, L.J., \& Hiles, D. R. (2018). Exploring the felt sense of chronic-ill health: dialoguing between IPA, lifeworld theory and narrative inquiry to make sense of feelings and affect. Qualitative Research in Psychology. DOI: 10.1080/14780887.2018.1499839. 
Lesley, too, described how she struggled to make sense of her partner's diagnosis, only coming to realise its significance when she saw it in the faces of those breaking the news:

\begin{abstract}
"I knew that I'd read it was long term, but I couldn't absorb that, er and really accept it and I had a close member of family who'd been an auxiliary nurse, who knew exactly what it would lead to who didn't tell me, but I could tell from their facial expressions when talking about Parkinson's disease er that they, it, there was something more to it than just an illness that would go away." (Lesley, partner)
\end{abstract}

The disturbance of mood here was two-fold (see agitation in Table 2): Lesley was upset with her family member for not being honest with her about the severity of the condition, and she was further distressed by the emotions displayed on the faces of those with whom she spoke about PD on receiving the diagnosis. This embodied affect is symbolically exchanged between those breaking the news and Lesley, demonstrating the resonance and reciprocity of emotional expression.

Ann, who was diagnosed with PD, told a poignant story of suffering that represented both the restless gloom and persecution of dwelling-mobility (see Table 2): she was prevented from organising the birthday cards for her family and friends. To Ann, this was not simply an organisational task; it was something she enjoyed, which brought joy to others. Her restless gloom represents the significance for her of no longer being able to show her affection and the persecution of feeling like an outsider being prevented from carrying out simple tasks that would bring her personal satisfaction:

\footnotetext{
"He even buys the birthday cards now, we, which was everything I used to do, in fact he's taken over my diary. I feel taken over." (Ann, diagnosed with PD)
}

Shaw, R.L., Smith, L.J., \& Hiles, D. R. (2018). Exploring the felt sense of chronic-ill health: dialoguing between IPA, lifeworld theory and narrative inquiry to make sense of feelings and affect. Qualitative Research in Psychology. DOI: 10.1080/14780887.2018.1499839. 
This feeling of persecution is reiterated in subsequent descriptions from Ann's account, in addition this makes Ann feel a lack of control and agency described by the $I$ am fragmented element of dwelling-mobility (See Table 2): Ann's sense of self became threated as her partner took away her sense of agency and independence that she has always been use to. To Ann this was an additional change to her lifestyle that felt intolerable:

"I also get peeved when he runs my bank account and takes over my diary and generally erm generally takes away any independence I might have, which I feel that, it actually, by eradicating this, this independency, it makes it more difficult to cope with the diagnosis."

Despite this impediment, there is a sense of hope in Ann's account, illustrating the possibility for co-existing feelings of at-homeness (see the 'dwelling' sense of spatiality in Table 1) and homelessness. Ann compared herself to a bird with a broken wing, but she was defiant that she would "float back up again". This represents an opportunity for well-being, a sense of reconciliation with her situation - getting back up again despite her diagnosis (see peacefulness of mood in Table 1). Ann also recognises that with the support of others there is opportunity for well-being and a sense of moving forward despite obstacles (see I can of identity in Table 1):

"What I do is make quite sure that I seek help immediately and get myself back on the rails again.”

Ann's determination to continue moving forward and recognition that "the quicker you come to terms with it the easier things become" demonstrates Ann's resolve to 
experience well-being despite the challenges and decreasing lack of self agency she faces.

Susan also found a sense of reconciliation, or attunement, with her partner's diagnosis:

“It's like anything, it's like the unknown, it, that's the frightening bit what we're living through is just our lives, it's not, this isn't the nightmare, it's just our lives with that thrown in, if you see what I mean.” (Susan, partner)

There may be peaks and troughs, but it seems that this flow between agitation of suffering (Table 2) and peacefulness of well-being (Table 1) represented Susan's journey of coming to terms with the diagnosis; moving forward so that the unknown became the known, and dealing with the unfamiliar became the modus operandi.

Jane described a pro-active attempt to be with her partner through his PD. Jane's partner, Albert has since died, but Jane reflected on her experience of making a life of togetherness in spite of Albert's PD. The feeling tone of Jane's account is positive, reflecting her determination to experience well-being within her experience of living with PD (see mutual complementarity in Table 1):

“I didn't have a life of my own, but we did things together because I made it that way otherwise, well, you wouldn't go out, would you?" (Jane, partner)

Susan's partner, Richard, displayed a similar sense of togetherness in the reciprocal wealth of emotion passing between him and his partner since his diagnosis:

"I mean we sort of found out our feelings for each other have sort of multiplied.

We've got a lot more time for each other." (Richard, diagnosed with PD)

Shaw, R.L., Smith, L.J., \& Hiles, D. R. (2018). Exploring the felt sense of chronic-ill health: dialoguing between IPA, lifeworld theory and narrative inquiry to make sense of feelings and affect. Qualitative Research in Psychology. DOI: 10.1080/14780887.2018.1499839. 
These feelings built a foundation upon which well-being could be experienced in amongst the uncertainty and agitation. This feels like more than a sense of making the best of it. For Richard, the love which was rekindled between himself and Susan opened up a new opportunity for intimacy and thus created a mirror-like multidimensional fullness (see the 'dwelling-mobility' of mood in Table 1). This is an experience of wellbeing, reflecting dwelling-mobility, which offers both an energetic enthusiasm for what is to come, and a feeling of being at one with oneself, being able to let be, and experience a contentedness with the now. Susan's emotional attunement also displayed signs of this contented union between the now and what is to come:

"We do what we wanna do now, you know, we've had a bit of a tough few years so yeah, we're making it our time now." (Susan, partner)

This analysis has revealed the presence of contradictory emotions within the experience of living with PD. For those with the diagnosis and their partners there were opportunities for well-being, but also evidence of suffering. The feelings within the accounts were fresh, as if being re-lived through the telling of their experiences. By focusing on mood/emotional attunement in this lifeworld analysis, new interpretations were made of the felt sense of PD which revealed something of the texture of the experience of living with this chronic illness. Feelings fluctuated and were relational; they flowed back and forth between a sense of at-homeness and homelessness, and existed in between people in that intersubjective space which creates so much of who we are and how we live. Using the lifeworld theory enabled us to pay close attention to the finer details of lived experience, which can easily be missed when working at the 
level of an experiential account instead of breaking down that account into elements of the lifeworld in order to build a more nuanced and deeper analysis.

\section{Narrative oriented inquiry analysis}

A number of different psychological approaches to narrative analysis have now emerged over the past several decades. The earliest of these drew upon linguistic theory, developed by Labov \& Waletzky (1967) that emphasises the structure of narrative discourse. Another approach emphasises the discursive and performative aspects of the social context of narrative (Mishler, 1986; Emerson \& Frosh, 2004; Bamberg, 2012); and yet another approach asks "why was a story told in this particular way" (Riessman, 2008). However, NOI offers a detailed methodology that incorporates all of these different theoretical positions into an integrated and systematic model for narrative inquiry. NOI offers an abductive approach to qualitative analysis because it draws explicitly upon narrative theory to drive the analysis of data.

Table 3 is a demonstration of NOI analysis of an extended narrative taken from Susan's interview. The left-hand column of this table presents the uninterrupted narrative that is presented as 18 segments by breaking the raw transcript down into a sequence of segments, episodes, or 'moves'. This breakdown into segments is merely to facilitate the later steps in the data analysis. The segments are then numbered for the ease of cross-reference later. At this stage, the text in the left-hand column is broken down into its two underlying but interrelated components: into sjuzet and fabula, which Herman \& Vervaeck (2001) characterize as the "unbounded" and "bounded" motifs of narrative structure. In practice, this corresponds to "how the story is being told" and 
"the sequence of events being related" respectively. By convention, in Table 3 the sjuzet is underlined.

[insert Table 3 around here]

At this first stage of the analysis, it is especially interesting to read out loud the fabula (i.e. the part of the transcript that is not underlined). The fabula simply relates a temporal storyline, and reads strikingly dull, or 'flat', in its presentation of events, lacking any emphasis, drama or justification in the re-telling of the story, but provides merely a basic "story line" for the core narrative. On closer examination it becomes obvious that it is the sjuzet that reveals a rich expression of the felt sense of experience, providing richness and depth to the meaning-making of feeling and affect.

The right-hand column of the table details the coding of the narrative, with the emphasis here placed especially on (i) the overall structure, and (ii) the subtle expression of emotion, feeling, affect and mood, which emanates almost entirely from the sjuzet.

In principle NOI does not set out to infer and impose an underlying narrative scheme upon data from any interview or conversation, but works only on data that is explicitly of a story form. The approach to NOI data analysis used in this paper is concerned with identifying the subtle competencies implicated in the narrator's story, which Hiles Čermák \& Chrz, (2017) characterize as a "human narrative intelligence". The NOI data coding strategy would normally involve cognitive, discursive, praxis, cultural, imaginative and Aeolian codes proposed by Hiles Čermák \& Chrz (2017), but because of the nature of the focus of this research, a variation is being used here.

Briefly, the basic steps and conventions for this NOI analysis presented in Table 3 are as follows:

Shaw, R.L., Smith, L.J., \& Hiles, D. R. (2018). Exploring the felt sense of chronic-ill health: dialoguing between IPA, lifeworld theory and narrative inquiry to make sense of feelings and affect. Qualitative Research in Psychology. DOI: 10.1080/14780887.2018.1499839. 
Step 1: This involves coding that is capitalized and placed within brackets, e.g. (SETTING) and outlines the basic narrative structure (i.e. ABSTRACT, SETTING, COMPLICATION, EVALUATION, RESULT, CODA) first outlined by Labov \& Waletsky (1967). This is particularly complex in Susan's story of her partner's experience of the trials and tribulations of diagnosis. Of particular interest in this first step of the analysis is the coding that identifies four different SETTINGS for the action of the unfolding story. The four settings are encoded by the fabula. Alongside the settings, seven COMPLICATIONS unfold in the telling of the story. These complications arise jointly out of (i) the action of the fabula, and (ii) the emotional reaction coded in the sjuzet. That there are seven COMPLICATIONS coded for a story of this length is somewhat unusual, but probably reflects the seriousness of the diagnostic process being recounted, as well as the discursive context of the style of interview being used.

Step 2: IP1, IP2 etc. correspond to the several distinct identity positions that are coded in the sjuzet of the storytelling, which reflect the progress of the action in the fabula. Stories are not a resumé of events, but are a re-telling, on a particular occasion, in a particular way, from a particular point of view (Hiles, 2007). The narrator creates identity positions for themself with respect to the flow of events that reflect their felt sense of mood. In the case of Susan, she adopts a sequence of four distinct identity positions: (i) concern for partner, (ii) medical confirmation that his face has changed, (iii) responsibilities to family, and (iv) relief that her partner's disorder is not terminal.

Step 3: Reflecting the emphasis of this NOI analysis on emotion, in the righthand column the words written in Bold/Italics, e.g. anxiety/confusion, code the expression of emotion, feeling, and affect. Therefore the conclusion from this NOI health: dialoguing between IPA, lifeworld theory and narrative inquiry to make sense of feelings and affect. Qualitative Research in Psychology. DOI: 10.1080/14780887.2018.1499839. 
analysis is that the coding of emotion, feeling, and affect is found almost exclusively in the sjuzet, which the fabula seems to entirely efface. Furthermore, the impression from the coding of the sjuzet for this particular type of narrative is of a rollercoaster of emotions through the diagnostic process and the necessary adjustment involved, i.e. emotions of anxiety, confusion, explanation in retrospect, surprise, embarrassment, awkwardness, commitment, support and so on, and on.

The coding of mood (cf. Galvin \& Todres, 2013, p.29) is however more subtle and impressionistic. In our judgement, the mood that most obviously stands out in Susan's story is one of "concern", which is expressed overtly and subtly across the entire narrative with respect to each of the four identity positions. The mood of "concern" is similarly found in the interviews of the other participants.

The final point to emphasise from this NOI coding and data analysis is that it is explicitly abductive in its approach. The coding explicitly involves a process of inference to best explanation (Hiles, 2014). As with applying lifeworld analysis in the previous phase of our research, rather than theory emerging from out of the data, NOI coding of narrative data draws upon a wide range of existing psychological, linguistic, discursive, and cultural constructs that are drawn into the analysis. The implications of this for the field of qualitative inquiry has been discussed further by Hiles, Čermák \& Chrz (2017).

\section{Discussion}

The analysis presented here considerably extends the original IPA analysis which resulted only in generating a set of four 'themes' describing the lived experience of PD. The lifeworld analysis demonstrated the co-existence of well-being and suffering 
within participants' experiences of living with PD. This suggests a flow, rather than a dichotomy of opposed positions, between the emotional expression of well-being and suffering. This emphasises the situatedness of our lived experience; we cannot make sense of human phenomena such as living with chronic ill-health in isolation. The lifeworld analysis offered a holistic approach to understanding the relational aspects of living with PD, which shone through in the analysis of mood/emotional attunement. The 'mood-as-atmosphere' was evident in the meanings participants attached to their experiences. The emotions re-lived in the telling brought to life the texture of this experience.

The analysis using NOI focuses on one small narrative account of one participant and demonstrated the significant sense of "concern" within the story of coming to terms with a diagnosis of PD of her partner. When the fabula is "bracketed", the power of the sjuzet was revealed. Without the sjuzet, the story was flat, black and white; with the sjuzet reinstated, the narrative was told in full technicolour, and turned from a surface level description of an experience to a re-living, an experiencing, of the emotions embedded within the phenomenon of living with PD, i.e. that felt sense. In short, the sjuzet constituted the sustained expression of the participant's prevailing mood. This analysis was undertaken on a small section of one transcript to function as an illustration. This is a time consuming method but one which adds so much texture. We therefore do not necessarily propose its use on large data sets, but as an additional technique used on data subsets or case studies to draw out the depth of emotion as narrated often hidden in plain sight in experiential accounts.

Together, the phenomenological theory of the lifeworld and NOI offer approaches to analysis which speak to the wider theorisation of the role of emotion and 
affect in relation to what it means to be human and the ways in which we communicate or display those emotions through our intersubjectivity and our social interactions. Indeed, it might be suggested that the phenomenological and narrative approaches to qualitative analysis have an important close attunement in their analysis of human experience, with the phenomenological emphasising the nature of that experience and the narrative emphasising its universal mode of expression. We believe, therefore, that this work furthers the project of pluralism in qualitative psychology by exploring new ways of bringing together conceptualisations of human experience from different, but closely related schools of thought, much as Langdridge (2007) did in his proposed Critical Narrative Analysis which also draws from the narrative and phenomenological traditions.

A holistic approach to making sense of emotion, feeling and affect must surely accommodate both the macro and the micro in this way. Moreover, as suggested earlier, this playfulness with paradigms is cause for celebration. Now that qualitative psychology is secure in itself, we are able to test out new ideas, be creative with our old ways of thinking, and innovate. Of course, there are many ways in which researchers might be pluralist in their work - we are presenting just one possibility.

The other achievement of this proposed new approach is its adoption of abductive reasoning as a strategy for analysis. This will be new to many readers, but of course it is not a new approach. Again, the maturity of qualitative research in psychology, we argue, offers an opportunity to do things differently. What we have done here breaks the mould of the inductive qualitative method of analysis that means so much to many qualitative researchers. To adopt inductive reasoning is a symbol of 
the critical psychology movement which championed qualitative methods as a reaction against the hypothetico-deductive method of the positivist paradigm.

Embracing the notion of dialoguing with theory in order to make sense of research findings as part of the analytic process may be too far for some people! However, we propose that many qualitative methods of analysis come already with embedded theoretical concepts which aid our sense-making (e.g. rhetorical devices such as three-part lists and extreme case formulations, characterisation, plot, being-in-theworld, agentic meaning-making) but which we perhaps do not conceive of in that way. We argue that the approach we have taken here has explicitly outlined the roles played by data, theory and analytic processes in order to offer a transparent methodology for the exposition of feeling, emotion and affect within subjective lived experience.

Of course this work is limited to the worked example presented. We would love to see replications of this approach with different data to further explore its appropriateness for making sense of feeling, emotion and affect. Furthermore, although pluralist in our approach, we have combined two paradigms - phenomenology and interpretivism - with close conceptual ties. Additional methodological work could explore the possibilities of combining the phenomenological and the discursive.

\section{Conclusion}

This paper has proposed a new approach for making sense of emotion, feeling and affect within subjective lived experience. We combined the phenomenological theory of the lifeworld with a fine-grained analysis of the narrative structure of experiential accounts using NOI. The analysis involved abductive reasoning in order to find the best explanation for the findings by using both theory and data in tandem. The 
findings generated new interpretations demonstrating the deep penetration of mood throughout people's experiential accounts thus identifying emotion, feeling and affect as fundamental to what makes us human.

\section{References}

Ashworth, PD, 2006, 'Seeing oneself as a carer in the activity of caring: Attending to the lifeworld of a person with Alzheimer's disease', International Journal of Qualitative Studies on Health and Well-being, vol. 1, pp. 212-225.

Bamberg, M, 2012, Why narrative? Narrative Inquiry, vol. 22(1), pp.201-212.

Barnett, M, 2005, 'Chronic obstructive pulmonary disease: a phenomenological study of patients' experiences', Journal of Clinical Nursing, vol. 14(7), pp. 805-812.

Bury, M, 2001, 'Illness narratives: fact or fiction?' Sociology of Health \& Illness, vol. 23(3), pp. 263-285.

Delbene, R, 2011, Patients' narratives of chronic illnesses and the notion of biographical disruption. Communication \& Medicine, vol. 8(1), pp. 17-27.

Dahlberg, K, Dahlberg, H \& Nyström, M, 2008, Reflective lifeworld research ( $\left.2^{\text {nd }} \mathrm{ed}.\right)$, The authors and Studentlitteratur.

Ekra, EMR, \& Gjengedal, E, 2012, 'Being hospitalized with a newly diagnosed chronic illness - a phenomenological study of children's lifeworld in the hospital', International Journal of Qualitative Studies in Health and Well-being, vol. 7, 18694, doi:10.3402/qhw.v7i0.18694.

Emerson, P, \& Frosh, S, 2004 Critical narrative analysis in psychology. Basingstoke, Palgrave Macmillan.

Fine, M \& Glendinning, C, 2005, Dependence, independence or inter- dependence?

Revisiting the concepts of 'care' and 'dependency', Ageing \& Society, vol. 25 pp. 601-621.

Frost, NA, Nolas, S-M, Brooks-Gordon, B, Esin, C, Holt, A, Shinebourne, P \& Mehdizadeh, L, 2010, 'Pluralism in qualitative research: the impact of different researchers and qualitative approaches on the analysis of qualitative data', Qualitative Research, vol. 10, no.4, pp. 441-460.

Shaw, R.L., Smith, L.J., \& Hiles, D. R. (2018). Exploring the felt sense of chronic-ill health: dialoguing between IPA, lifeworld theory and narrative inquiry to make sense of feelings and affect. Qualitative Research in Psychology. DOI: 10.1080/14780887.2018.1499839. 
Frost, NA, 2011, Qualitative research methods in psychology: combining core approaches, London, Open University Press.

Frost, NA Holt, A Shinebourne, P Esin, C Nolas, S-M Mehdizadeh, L, \& BrooksGordon, B. 2011, Collective findings, individual interpretations: an illustration of a pluralistic approach to qualitative data analysis, Qualitative Research in Psychology, vol. 8 pp.93-113.

Galvin, K, \& Todres, L, 2013, Caring and well-being: a Lifeworld Approach. London and New York, Taylor and Francis Group.

Gendlin, E, 1981, Focusing. New York, Bantam.

Giorgi, A, 2009, The descriptive phenomenological method in psychology: a modified Husserlian approach, Pittsburgh, PA, Duquesne University Press.

Glynos, J \& Howarth, D, 2007, Logics of critical explanation in social and political theory, London, Routledge.

Gullick, J \& Stainton, MC, 2008, 'Living with chronic obstructive pulmonary disease: Developing conscious body management in a shrinking life-world', Journal of Advanced Nursing, vol. 64(6), pp. 605-614.

Haar, A, Kirkevold,M, Hall, EOC, \& Ostergaard, K, 2011, Living with advanced Parkinson's disease: A constant struggle with unpredictability. Journal of Advanced Nursing, vol. 67(2), pp. 408-417.

Heidegger, M, 1962, Being and time (trans. J Macquarie \& E Robinson), New York, Harper \& Row.

Heidegger, M, 1993a, 'Building, dwelling, thinking', in DF Krell (ed.) Basic writings: Martin Heidegger, London, Routledge, pp. 343-364.

Heidegger, M, 1993a, 'Origin of the work of art', in DF Krell (ed.) Basic writings: Martin Heidegger, London, Routledge, pp. 83-140.

Herman, L \& Vervaeck, B, 2001, Handbook of narrative analysis, Lincoln, NB, University of Nebraska Press.

Hiles, DR, 2014, 'Qualitative inquiry, mixed methods and the logic of scientific inquiry', Qualitative Methods in Psychology, vol. 17, pp. 49-62.

Hiles, DR, 2007, 'Identity positioning: Narrative analysis of sjuzet and fabula', in D Robinson, N Kelly \& K Milnes (eds.), Narrative and Memory, Huddersfield, University of Huddersfield Press.

Shaw, R.L., Smith, L.J., \& Hiles, D. R. (2018). Exploring the felt sense of chronic-ill health: dialoguing between IPA, lifeworld theory and narrative inquiry to make sense of feelings and affect. Qualitative Research in Psychology. DOI: 10.1080/14780887.2018.1499839. 
Hiles, DR, Čermák, I \& Chrz, V, 2017, 'Narrative inquiry', in C. Willig \& W. StaintonRogers (eds.), The sage handbook of qualitative research in psychology $\left(2^{\text {nd }}\right.$ ed.), London, Sage Publications, pp. 157-175.

Husserl, E, 1936/1970, The crisis of european sciences and transcendental phenomenology: an introduction to phenomenological philosophy, (trans. D Carr), Evanston, IL, Northwestern University Press.

Labov, W \& Waletzky, J, 1967, 'Narrative analysis: oral versions of personal experience', in J Helm (ed.), Essays on the verbal and visual arts, Seattle, WA, University of Washington Press.

Langdridge, D, 2007, Phenomenological psychology: theory, research and method, Harlow, Essex, Pearson Prentice Hall.

Mishler, EG, 1986, Research interviewing: context and narrative, Cambridge, MA, Harvard University Press.

Mishler, EG, 1999, Storylines: craftartist's narratives of identity, Cambridge, MA, Harvard University Press.

Peirce, CS, 1903, Pragmatism as the logic of abduction ( $7^{\text {th }}$ Havard Lecture), The Essential Peirce, Vol 2, Indiana University Press.

Phillips, LJ, 2006, 'Dropping the bomb: The experience of being diagnosed with Parkinson's disease', Geriatric Nursing Journal, vol. 27, pp. 362-369.

Pierret, J, 2003, 'The illness experience: state of knowledge and perspectives for research', Sociology of Health \& Illness, vol. 25(3), pp. 4-22.

Reynolds, F \& Vivat, B, 2006, 'Narratives of art-making in chronic fatigue syndrome/myalgic encephalomyelitis: three case studies', Arts in Psychotherapy, vol. 33, pp. 435-445.

Ricœur, P, 1985, Time and narrative, vol. 2, (K McLaughlin \& D Pellauer, transl.), Chicago, IL, University of Chicago Press.

Riessman, CK, 1993, Narrative analysis, London, Sage Publications.

Riessman, CK, 2008, Narrative methods for the human sciences, London, Sage Publications.

Shapiro, J, 2011, 'Illness narratives: reliability, authenticity and the empathic witness', Medical Humanities, vol. 37(2), pp. 68-72.

Shaw, R.L., Smith, L.J., \& Hiles, D. R. (2018). Exploring the felt sense of chronic-ill health: dialoguing between IPA, lifeworld theory and narrative inquiry to make sense of feelings and affect. Qualitative Research in Psychology. DOI: 10.1080/14780887.2018.1499839. 
Shaw, RL \& Hiles, DR, 2017, 'Using multiple methods in applied qualitative research', in J Brooks \& N King (eds.) Applied qualitative research in psychology, London, Macmillan Education Palgrave, pp. 237-250.

Smith, JA, Flowers, P, \& Larkin, M, 2009, Interpretative phenomenological analysis: theory, method and research, London, Sage.

Smith, LJ, \& Shaw, RL, 2016, 'Learning to live with Parkinson's disease in the family unit: an interpretative phenomenological analysis of well-being', Medicine, Health Care and Philosophy, vol. 20, pp, 13-21.

Snelgrove, S, \& Liossi, C, 2009, 'An interpretative phenomenological analysis of living with chronic lower back pain', British Journal of Health Psychology, vol. 14(4), pp. 613-816.

Willig, C, 2017, 'The case for combining FDA and IPA in a dual focus methodology', symposium at the Qualitative Methods in Psychology Section Conference, Aberystwyth, 5-7 $7^{\text {th }}$ July. 
Shaw, R.L., Smith, L.J., \& Hiles, D. R. (2018). Exploring the felt sense of chronic-ill health: dialoguing between IPA, lifeworld theory and narrative inquiry to make sense of feelings and affect. Qualitative Research in Psychology. DOI: 10.1080/14780887.2018.1499839. 
Table 1: Dwelling-mobililty lattice of well-being

\begin{tabular}{|c|c|c|c|}
\hline $\begin{array}{l}\text { Element of the } \\
\text { lifeworld }\end{array}$ & Mobility & Dwelling & Dwelling-mobility \\
\hline Spatiality & $\begin{array}{l}\text { Adventurous horizons } \\
\text { Anything that offers a place of } \\
\text { promise. A sense of adventure } \\
\text { where spatial possibilities arise } \\
\text { that offer movement } \\
\text { (metaphorically or literally). }\end{array}$ & $\begin{array}{l}\text { At homeness } \\
\text { A sense of being at-home, feeling } \\
\text { of being settled/still within the } \\
\text { physical environment. Familiar } \\
\text { and comfortable surroundings or } \\
\text { having familiar/personal objects } \\
\text { close-by. }\end{array}$ & $\begin{array}{l}\text { Abiding expanse } \\
\text { Both a feeling of at- } \\
\text { homeness with possibilities } \\
\text { for adventurous horizons. } \\
\text { Being deeply connected to } \\
\text { a place but also opportunity } \\
\text { to go further afield } \\
\text { (metaphorically or literally) }\end{array}$ \\
\hline Temporality & $\begin{array}{l}\text { Future orientation } \\
\text { Being energised by future } \\
\text { possibilities (metaphorical or } \\
\text { literal) which emphasize the } \\
\text { sense of flow, not being stuck. }\end{array}$ & $\begin{array}{l}\text { Present-centredness } \\
\text { Absorbed in the present in a way } \\
\text { that is desired. Sense of } \\
\text { belonging, being 'in the zone'. }\end{array}$ & $\begin{array}{l}\text { Renewal } \\
\text { Unification of future } \\
\text { possibilities with a } \\
\text { satisfaction with the now. } \\
\text { Rooted flow - a sense of } \\
\text { being absorbed in the now } \\
\text { and a welcome readiness } \\
\text { for the future }\end{array}$ \\
\hline \multirow[t]{2}{*}{ Intersubjectivity } & $\begin{array}{l}\text { Mysterious interpersonal } \\
\text { attraction }\end{array}$ & Kinship and belonging & Mutual complementarity \\
\hline & $\begin{array}{l}\text { In tune with interactional } \\
\text { possibilities and an attraction to } \\
\text { people's 'otherness', } \\
\text { understanding the mystery of } \\
\text { others. }\end{array}$ & $\begin{array}{l}\text { An effortless being together; 'we' } \\
\text { rather than 'l' and 'you'. }\end{array}$ & $\begin{array}{l}\text { Both a sense of } \\
\text { kinship/togetherness and } \\
\text { excitement at learning new } \\
\text { things - a 'homelike } \\
\text { oneness' and difference. }\end{array}$ \\
\hline \multirow[t]{2}{*}{ Mood } & Excitement or desire & Peacefulness & $\begin{array}{l}\text { Mirror-like multidimensional } \\
\text { fullness }\end{array}$ \\
\hline & $\begin{array}{l}\text { Sense of 'attunement' and } \\
\text { buoyancy of movement (looking } \\
\text { forward to a longed-for holiday } \\
\text { or special event). }\end{array}$ & $\begin{array}{l}\text { Stillness, settledness. There is a } \\
\text { welcomed pause, coming to } \\
\text { accept things, and 'letting be'. }\end{array}$ & $\begin{array}{l}\text { Complex mood } \\
\text { encapsulating an energy of } \\
\text { moving forwards and a } \\
\text { sense of being at one with } \\
\text { the world and oneself. }\end{array}$ \\
\hline Identity & $\begin{array}{l}\text { 'I can' } \\
\text { Sense of being able to. } \\
\text { Experiencing oneself as being } \\
\text { on the move (literally or } \\
\text { metaphorically). }\end{array}$ & $\begin{array}{l}\text { 'I am' } \\
\text { A sense of self that is supported } \\
\text { by continuous histories and } \\
\text { contexts that fit with who 'I am'. }\end{array}$ & $\begin{array}{l}\text { Layered continuity } \\
\text { A continuous sense of ‘l } \\
\text { can' and a strong sense of } \\
\text { 'just being' in a foundational } \\
\text { sense. Ontological security. }\end{array}$ \\
\hline Embodiment & $\begin{array}{l}\text { Vitality } \\
\text { Tuned into an embodied energy } \\
\text { that offers the possibility of } \\
\text { movement, 'bodying forth'. }\end{array}$ & $\begin{array}{l}\text { Comfort } \\
\text { Literal feeling of comfort, warmth, } \\
\text { relaxation. Felt sense of familiarity } \\
\text { and intimacy with one's body. }\end{array}$ & $\begin{array}{l}\text { Grounded vibrancy } \\
\text { An energized flow and a } \\
\text { bodily sense of feeling } \\
\text { deeply at-home. Both } \\
\text { 'being' and 'becoming' is } \\
\text { possible. }\end{array}$ \\
\hline
\end{tabular}

Shaw, R.L., Smith, L.J., \& Hiles, D. R. (2018). Exploring the felt sense of chronic-ill health: dialoguing between IPA, lifeworld theory and narrative inquiry to make sense of feelings and affect. Qualitative Research in Psychology. DOI: 10.1080/14780887.2018.1499839. 
Table 2: Dwelling-mobility lattice of suffering

\begin{tabular}{|c|c|c|c|}
\hline $\begin{array}{l}\text { Element of the } \\
\text { lifeworld }\end{array}$ & Mobility & Dwelling & Dwelling-mobility \\
\hline Spatiality & $\begin{array}{l}\text { Imprisoned } \\
\text { A sense of feeling hemmed in, } \\
\text { unable to move, trapped, with no } \\
\text { room or any horizon that can } \\
\text { give respite. }\end{array}$ & $\begin{array}{l}\text { Exiled } \\
\text { A sense of feeling cast out into an } \\
\text { inhospitable place, wrenched from } \\
\text { a familiar space, banished to an } \\
\text { alien place with limited opportunity } \\
\text { for relief or breathing space. }\end{array}$ & $\begin{array}{l}\text { Roomless } \\
\text { Both a feeling of longing for } \\
\text { home but being so trapped } \\
\text { in homelessness that there } \\
\text { is the despair of 'little or no } \\
\text { possibility'. }\end{array}$ \\
\hline Temporality & $\begin{array}{l}\text { Blocked future } \\
\text { A sense of temporal stagnation } \\
\text { and feeling blocked or cut off } \\
\text { from any sense of the future. } \\
\text { This constitutes to the sense of } \\
\text { feeling frozen in time, being } \\
\text { stuck. }\end{array}$ & $\begin{array}{l}\text { Elusive present } \\
\text { Being unable to simply 'be } \\
\text { present' due to unpleasantness of } \\
\text { the present moment or the 'pull' of } \\
\text { the past or the future. Sense of } \\
\text { unsettledness, being unable to } \\
\text { 'stand still'. }\end{array}$ & $\begin{array}{l}\text { No respite } \\
\text { A feeling of the present } \\
\text { being unliveable, with no } \\
\text { way forward so that neither } \\
\text { the future nor the present } \\
\text { provide possibilities of } \\
\text { respite. }\end{array}$ \\
\hline \multirow[t]{2}{*}{ Intersubjectivity } & Aversion & Alienated isolation & Persecution \\
\hline & $\begin{array}{l}\text { An aversion towards being with } \\
\text { another or others that polarises } \\
\text { the 'Me' from the 'You' in either } \\
\text { feeling the aversion or becoming } \\
\text { the victim of it. }\end{array}$ & $\begin{array}{l}\text { A ruptured sense of interpersonal } \\
\text { belonging and kinship. A literal or } \\
\text { existential loneliness. }\end{array}$ & $\begin{array}{l}\text { Others have become the } \\
\text { source of pain and threat } \\
\text { with a feeling that there is } \\
\text { no way out. A sense of } \\
\text { feeling like an outsider or } \\
\text { feeling victimised. }\end{array}$ \\
\hline \multirow[t]{2}{*}{ Mood } & Depression & Agitation & Restless gloom \\
\hline & $\begin{array}{l}\text { A 'closed in' mood of limited or } \\
\text { dark horizons and a felt inability } \\
\text { to move forward. Characterised } \\
\text { by a lack of energy and } \\
\text { motivation, an uninviting future, } \\
\text { a kind of dullness, a pessimistic } \\
\text { outlook. }\end{array}$ & $\begin{array}{l}\text { Unsettled restlessness } \\
\text { characterised by a feeling of } \\
\text { irritation, anxiety, disturbance, a } \\
\text { sense that something is wrong. }\end{array}$ & $\begin{array}{l}\text { Complex mood } \\
\text { encapsulating a feeling of } \\
\text { gloom that is intolerable; } \\
\text { the intensity of which } \\
\text { causes agitation to find a } \\
\text { way out. }\end{array}$ \\
\hline Identity & $\begin{array}{l}\text { I am unable } \\
\text { Sense of lacking ability. } \\
\text { Experiencing oneself as being } \\
\text { 'useless' or 'failed' (literally or } \\
\text { metaphorically). }\end{array}$ & $\begin{array}{l}\text { I am an object or 'thing' } \\
\text { A sense of self that is being } \\
\text { injured or deformed. An } \\
\text { awareness of being 'pinched' into } \\
\text { 'being what I am not'. }\end{array}$ & $\begin{array}{l}\text { I am fragmented } \\
\text { A coherent sense of self } \\
\text { has become fragmented, } \\
\text { carrying with it a sense of } \\
\text { personal impotence and } \\
\text { lack of agency. }\end{array}$ \\
\hline Embodiment & $\begin{array}{l}\text { Stasis and exhaustion } \\
\text { An inability or lack of desire to } \\
\text { move, or a felt sense of impaired } \\
\text { or threatened bodily functions. } \\
\text { Physical sensations that include } \\
\text { 'being stopped in one's tracks'. }\end{array}$ & $\begin{array}{l}\text { Bodily discomfort and pain } \\
\text { A difficulty to simply dwell or feel } \\
\text { at home in one's body because of } \\
\text { a palpable sensation that } \\
\text { something is wrong. }\end{array}$ & $\begin{array}{l}\text { Painful closing down } \\
\text { A felt sense of 'the body } \\
\text { closing down' or being } \\
\text { overwhelmed in } \\
\text { uncomfortable, painful or } \\
\text { depleted ways. }\end{array}$ \\
\hline
\end{tabular}

Shaw, R.L., Smith, L.J., \& Hiles, D. R. (2018). Exploring the felt sense of chronic-ill health: dialoguing between IPA, lifeworld theory and narrative inquiry to make sense of feelings and affect. Qualitative Research in Psychology. DOI: 10.1080/14780887.2018.1499839. 
1. The main problem to start with was the saliva issue. He seemed to be (was) producing a lot of saliva, but he wasn't, it was just that he wasn't swallowing properly, which we didn't know was a symptom.

2. Sometimes l'd look at him and, and l'd say to him "Your face looks different to me". It looked as if his mouth, his teeth were in the wrong place (laughs).

3. It sounds silly but, his teeth were in the wrong place.

4. We were at the doctor's one day for a check-up, cos he had had depression for a few years really, and, constantly going back and, you know, I mean he's okay ... no, he wasn't quite off medication.

5. So he had to go back, keep going back, and I use to go with him. And, she said I think we'll get this checked out because she said "your face looks different to me." And I said, "Well, strangely enough I had said that to him".

6. A little while ago she said "Is there any ...", that's when she said "Is there any Parkinson's in the family?"

7. And that was the first hint, that anything, you know might be wrong. And we said, "No, not that we knew of." (sigh).

8. And it isn't necessarily a thing that runs in families anyway, as we've since found out.

9. So she said .... "I think l'll refer you to the neurologist." Which she did. And it's quite a long time coming through, as these things are.

10. And in the meantime, we had a lot of stress with his mum's partner, with this illness that he had and because Richard was, he'd got family this guy but, he relied on Richard because his family didn't really want to know.

11. So, we obviously had a lot of his affairs to sort out and he actually eventually went into a care home.

12. And then there was the problem of his 87 year old mother, who was then left on her own in a village, isolated.

13. And eventually we did, well we did sort of talk to her about moving a bit closer, which she did.

14. But at the time, when we were waiting, his problems were actually put on the [back burner] because, we had so much else going on.

15. So I don't think we actually, even at the time, even when he was diagnosed, when we went to see the neurologist,

16. I really don't think that it [sank in].

17. He was quite relieved it wasn't anything terminal.

18. Cos I think he'd got suspicions that there was something more worse ...er... if you could get more than something like

Coding, notes \& comments:

(ABSTRACT - the main problem ...)

IP1: Concern for husband

anxiety/confusion (producing saliva, but wasn't!!)

didn't know - retrospective explanation

(SETTING 1 / COMPLICATION 1 - face is different) surprise/concern

laughs-embarrassment

silly-awkwardness

(SETTING 2-At the doctor's)

cos he had had depression ... - concern

he's okay - discounting

commitment, support

(COMPLICATION 2- doctor confirms face different)

IP2: face confirmed as looking different

strangely enough - oddly

(COMPLICATION 3 - any Parkinson's in the family?)

first hint - glimmer of threat; might be wrong -

threat; sigh - (discursive) realization

since found out - rationalization

(COMPLICATION 4 - referral to neurologist)

(COMPLICATION 5 - waiting)

as these things are - acceptance

(SETTING 3 - competing family demands) (COMPLICATION 6a - mum's partner) - stress IP3: feelings of responsibility to family

eventually - relief from stress

(COMPLICATION $6 \mathrm{~b}$ - his mum isolated)

eventually - resolution

(EVALUATION - subtle reflection)

[back burner] - metaphor: problem back of mind

(SETTING 4 - reflections on diagnosis)

[sank in] - metaphor: depth of original feelings

(RESULT) IP4: - shared relief of the concern that it might have been a terminal condition

(CODA - repressed affect - reflection on his suspicions that it might have been much worse)

Shaw, R.L., Smith, L.J., \& Hiles, D. R. (2018). Exploring the felt sense of chronic-ill health: dialoguing between IPA, lifeworld theory and narrative inquiry to make sense of feelings and affect. Qualitative Research in Psychology. DOI: 10.1080/14780887.2018.1499839. 
